Vielfache vermehren, dass nach der Natur der Pflanze und bei günstiger Beleuchtung, Temperatur u. s. w. die Gewichtsvermehrung der Trockensubstanz das Hundertfache des Samens erreichen und übersteigen kann, dass ferner die Pflanzen hierbei ihre normalen Formen entwickeln und endlich keimfähige Samen liefern können. Ich halte dafür, dass der Boden bei der Ernährung der Landpflanzen vermöge seiner Adhäsionskräfte begünstigend mitwirkt, dass aber der Boden auch für Landpflanzen keineswegs eine conditio sine qua non ist. In dieser Fassung ist der Gedanke der meinige, ich hoffe aber, dass er recht bald das Gemeingut aller Pflanzenphysiologen werden wird.

\title{
Nachs chrift
}

\section{von}

\section{A. Stoeckharat.}

Den vorstehenden Auseinandersetzungen des Dr. J. Sachs füge ich die Erklärung bei: dass ich die beregten Versuche des Dr. Sachs, zu deren Vornahme ich demselben ein besonderes Local meines Laboratoriums eingeräumt, beide Sommer (1859 und 1860) hindurch von $A n-$ fang bis zu Ende mit unausgesetzter Aufmerksamkeit verfolgt habe; dass von meinen Assistenten, namentlich Dr. Peters und Dr. Handtke, sich vielfach an diesen Versuchen betheiligt haben, und die ganzen Versuchszeiten hindurch in stetem Verkehr mit denselben und dem Dr. S a ch s gewesen sind, und dass wir auf Grund unserer persönlichen Wahrnehmungen und eignen sachlichen Erfahrungen das unbegründete Urtheil des Dr. Knop über diese Versuche, welche er nie gesehen, mit aller Entschiedenheit zurückzuweisen uns gedrungen fühlen. Dass die Gründe, welche Dr. Knop zur Rechtfertigung der Art seines Auftretens gegen meinen ehrenhaften jungen Freund und Mitarbeiter Dr. Sachs anführt, das letztere in keiner Weise zu rechtfertigen vermögen, wird Jeder finden, der sich die Mühe nehmen will, das, was ich selbst in meinem 
„chemischen Ackersmann" (1859, p. 28 u. 1860, p. 40 ff.) über die beregten Versuche veröffentlicht habe, mit den in den "Versuchsstationen" enthaltenen Sachs'schen und Knop'schen Aufsätzen zu vergleichen. Im 6. Hefte der letzteren, wie im 1. Heft des chemischen Ackersmanns pro 1861, sind die in noch höherem Grade gelungenen Versuche des Jahres 1860 nachzusehen.

Tharand, im Januar 1861.

\section{XLV. \\ Notize n.}

1) Ueber einen Apparat zum Auswaschen.der Niederschläge auf dem Filter.

Von

Dr. Ferdinand Bothe.

Die bisher bekannten derartigen Apparate erhalten ein constantes Niveau der Flüssigkeit auf dem Filter, sie fügen für jeden abfliessenden Tropfen einen neuen zu und bedingen so, zur nicht geringen Unbequemlichkeit des Arbeitenden, die Ansammlung beträchtlicher Flüssigkeitsmengen.

Der nachstehend beschriebene Apparat bringt diesen Uebelstand in Wegfall, und dürfte desshalb willsommen erscheinen.

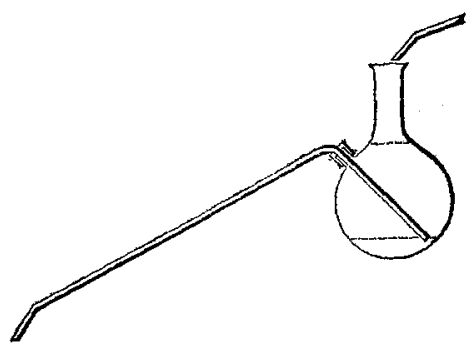

Derselbe besteht, wie Figur zeigt, in einem mit Seitenöffnung versehenen Kolben, welcher durch eine Tropflasche nach und nach gefüllt, durch einen zeitweilig wirkenden Heber schnell auf das Filter entleert wird. Das Spiel des letzteren beginnt, wenn die Oberfläche der 